\title{
BMJ Open Developing a core outcome set for infant colic for primary, secondary and tertiary care settings: a prospective study
}

\author{
Nina F Steutel, ${ }^{1,2}$ Marc A Benninga, ${ }^{1}$ Miranda W Langendam, ${ }^{2}$ Judith J Korterink, ${ }^{1}$ \\ Flavia Indrio, ${ }^{3}$ Hania Szajewska, ${ }^{4}$ Merit M Tabbers ${ }^{1}$
}

To cite: Steutel NF, Benninga MA, Langendam MW, et al. Developing a core outcome set for infant colic for primary, secondary and tertiary care settings: a prospective study. BMJ Open 2017;7:e015418. doi:10.1136/ bmjopen-2016-015418

- Additional material is published online only. To view please visit the journal online (http://dx.doi.org/10.1136/ bmjopen-2016-015418)

Received 2 December 2016 Revised 27 January 2017 Accepted 6 March 2017

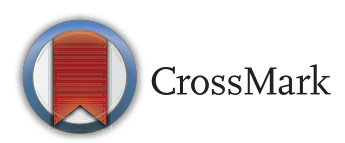

${ }^{1}$ Department of Paediatric Gastroenterology and Nutrition, Emma Children's Hospital, Academic Medical Centre, Amsterdam, The Netherlands ${ }^{2}$ Department of Clinical Epidemiology, Biostatistics and Bioinformatics, Academic Medical Centre, Amsterdam, The Netherlands

${ }^{3}$ Department of Paediatrics, Giovanni XXIII Hospital, University of Bari, Bari, Italy ${ }^{4}$ Department of Paediatrics, The Medical University of Warsaw, Warsaw, Poland

Correspondence to

Nina F Steutel;

n.f.steutel@amc.uva.nl

\section{ABSTRACT}

Objective Infant colic (IC) is defined as recurrent and prolonged crying without an obvious cause or evidence of failure to thrive or illness. It is a common problem with a prevalence of $5 \%-25 \%$. The unknown aetiology results in a wide variety in interventions and use of heterogeneous outcome measures across therapeutic trials. Our aim was to develop a core outcome set (COS) for IC to facilitate and improve evidence synthesis.

Design and setting Prospective study design; primary, secondary and tertiary care.

Methods The COS was developed using a modified Delphi technique. First, healthcare professionals (HCPs) and parents of infants with IC were asked to list up to five outcomes they considered relevant in the treatment of IC. Outcomes mentioned by $>10 \%$ of participants were forwarded to a shortlist. In the second round, outcomes on this shortlist were rated and prioritised. The final COS was defined in a face-to-face expert meeting of paediatricians. Results $\mathrm{F}$ of invited stakeholders (133 HCPs and 55 parents of infants with IC) completed both Delphi rounds. Duration of crying, family stress, sleeping time of infant, quality of life (of family), discomfort of infant and hospital admission/duration were rated as most important outcomes in IC, framing the final COS.

Conclusions The use of this COS should serve as a minimum of outcomes to be measured and reported. This will benefit evidence synthesis, by enhancing homogeneity of outcomes, and enable evaluation of success in therapeutic trials on IC. Researchers are strongly encouraged to use this COS when setting up a clinical trial in primary, secondary and/or tertiary care or performing a systematic review on IC.

\section{BACKGROUND}

Infant colic (IC) is a common problem with an estimated prevalence of 5\%-25\%. ${ }^{1-4}$ Diagnostic criteria, formulated by the Rome IV committee, are recurrent and prolonged periods of crying without an obvious cause or evidence of failure to thrive or illness in infants younger than 5 months.

Although IC is self-limiting, it may have negative short-term and/or long-term consequences. It has been postulated that, for example, a disturbed parent-infant interaction, child
Strengths and limitations of this study

Healthcare professionals and parents of infants with infant colic were involved in a modified Delphi procedure to ensure appropriate outcomes are measured.

- Including stakeholders from around the globe increases the applicability of this core outcome set.

- During the translation of the questionnaires and answers, subtle changes in questions or answers might have occurred and answers may have been misinterpreted.

abuse, recurrent abdominal pain, migraine, allergy, hyperactivity and learning problems occur more often in children with (a history of) IC. ${ }^{6-13}$ In addition, IC is associated with the development of postpartum depression in mothers. ${ }^{14}{ }^{15}$ Furthermore, IC can lead to feeding changes, medication use, paediatrician or emergency department visits, hospitalisation and loss of parental working days. ${ }^{416}$

Despite decades of research, the aetiology of IC remains unknown. Many theories exist, ranging from changes in the enteric nervous system, alterations in gut motility and microbiota, to different functioning of the central nervous system, allergy and early adverse life events. ${ }^{17}$ This diversity leads to a wide variety of interventions. Consequently, the unknown aetiology also leads to the use of heterogeneous outcome measures in trials of IC. Heterogeneity in defining and measuring outcomes impedes comparison of results between trials regarding the efficacy of an intervention. ${ }^{18}$

In several paediatric fields, such as asthma and acute diarrhoea, the Delphi technique was used to identify outcomes, relevant to both clinicians and parents, and instruments to measure these outcomes. ${ }^{19-21}$

Given the current lack of agreement on definitions and outcomes for IC, it is necessary to develop a core outcome set (COS). ${ }^{22}$ This 
need has been affirmed by the Rome IV committee. ${ }^{5} \mathrm{~A}$ COS describes the agreed minimum set of outcomes that should be measured and reported in all trials in a specific area. They increase consistency across efficacy trials, maximising the potential for trials to be included in a meta-analysis. This will enhance consensus about the efficacy of an intervention. For example, Xu et $a l^{23}$ published a meta-analysis about the efficacy of probiotics for IC, including six randomised controlled trials (RCTs). They conclude that their study is limited by the heterogeneity of outcomes in the included trials and that their results should be interpreted with caution. Standardising the minimum amount of outcomes to be measured can reduce outcome heterogeneity and selective outcome reporting.

Furthermore, a COS enables comparison of trials and prevents healthcare professionals (HCPs) from overlooking important outcomes when treating patients with IC or when setting up a new trial or systematic review (SR) for IC. In addition, if stakeholders are involved in the development, a COS makes it more likely that appropriate outcomes are measured. ${ }^{24}$

The need to improve outcome measurement was first recognised by formation of the Outcome Measures in Rheumatology (OMERACT) initiative in 1992. This international network focuses on improving outcome measurement in rheumatology. ${ }^{25}$ The launch of the COMET (Core Outcome Measures in Effectiveness Trials) Initiative in January 2010 reinforced the need for the development of COS in other fields of medicine. The COMET Initiative aims to bring people together that are interested in the development of COS. ${ }^{24}$

In 2012, the Consensus Group on Outcome Measures Made in Pediatric Enteral Nutrition Clinical Trials (COMMENT) was established by the European Society for Paediatric Gastroenterology, Hepatology and Nutrition (ESPGHAN) for this purpose. Six working groups were established to develop a COS for clinical trials in different areas, including IC. ${ }^{21}{ }^{26}$ In this article, we describe the development of a COS for infants with IC to enable evaluation of effectiveness in therapeutic trials of IC, in primary, secondary and tertiary care settings.

\section{METHODS}

The project consists of four steps: preparation (step 1), identifying outcomes (step 2), development of a COS (step 3) and measurement of the COS (step 4). This article describes the second and third step, using the Core Outcome Set - STAndards for Reporting (COS-STAR) statement to benefit reporting (see Supplementary file). ${ }^{2027}$

\section{Registry entry}

This study was not registered.

\section{Ethical approval and consent to participate}

The Medical Ethics Review Committee confirmed that the Medical Research Involving Human Subjects Act
(Wet medisch-wetenschappelijk onderzoek met mensen, WMO) did not apply to this study, and therefore official approval by the committee was not required.

\section{Data analysis}

Descriptive statistics were used to summarise our results.

\section{Step 1-Preparation: reporting outcome measures in trials of IC}

This step consisted of identifying which outcomes related to IC were reported in (SRs of) therapeutic RCTs. The databases CENTRAL, Embase, and MEDLINE/PubMed were searched from inception to December 2012. English language SRs (of RCTs) and RCTs concerning IC in children aged 0-9 months were included. Reference lists of included SRs were searched for additional articles. This was published previously. ${ }^{18}$

\section{Step 2-Identifying important treatment outcomes (HCPs and parents)}

The first aim of this step was to identify which outcomes are used by HCPs when treating IC.

As the best strategy to select outcomes for clinical trials in paediatrics is unknown, we adhered to the methodology as defined by the COMMENT Working Group. ${ }^{21} 28$

We did not predefine a long list of outcomes based on the outcome measures mentioned, but instead invited HCPs visiting two international paediatric gastroenterology conferences in 2014 to participate in our survey. HCPs were eligible if they worked in primary, secondary and/or tertiary care and had experience with the treatment of infants with IC. We did not specify a priori which subgroup of HCPs had to be included. Participants were handed an English questionnaire on paper. They were asked to list up to five harmful and/or beneficial treatment outcomes for IC (definition was given), which they considered important and that guided their clinical decision-making. Separate questions were asked for the outpatient and inpatient settings because outcomes may differ between these settings (such as symptom severity or parental burden). Informed consent was assumed if an HCP completed the questionnaire. Data were collected on professional background and country of practice. This questionnaire was completed at the conference. Answers were processed anonymously. We did not perform a sample size calculation. On the basis of the study of Karas et $a l,{ }^{21}$ we aimed to include at least $100 \mathrm{HCPs}$.

The second aim of this step was to assess which treatment outcomes were relevant to parents of infants with IC. We aimed to include a total of 50 parents, ${ }^{20}$ in five different countries (Croatia, Italy, Poland, Portugal and The Netherlands). Parents were eligible for inclusion if they consulted a healthcare professional because their infant was diagnosed with IC. They were randomly invited to participate by their infant's doctor at the (general) paediatric outpatient clinic, representing primary, secondary and/or tertiary care. After oral informed consent, parents were asked to list up to five treatment outcomes 
for IC (definition was given) that made them feel their child was being treated adequately or made them feel comfortable. Because outcomes that make parents worry could differ, they were also asked to list up to five treatment outcomes that made them feel their child was being treated inadequately or made them feel uncomfortable. Demographic data were not collected. This questionnaire was completed at the outpatient clinic or by telephone. Answers were processed anonymously. The questionnaire was originally developed in English, but was provided to parents in their mother tongue. Answers were carefully translated back to English by the HCPs who invited the parents.

\section{Step 3a-Creating a shortlist}

First, listed outcomes were classified in domains. Domains functioned as subcategory to group outcome measures with similar characteristics. Domains were predefined based on our findings in step 1 (SR on outcomes ${ }^{18}$ ), supplemented with domains we considered to be relevant (such as 'quality of life' and 'costs') and domains that emerged from the respondents answers (such as 'growth' and 'medication').

Reported outcomes were combined when considered appropriate (by NFS and MMT). For example, 'less (time) crying', 'duration of crying', 'crying', 'number of hours crying per day/week', 'number of days/week without crying $>3$ hours', 'patient with crying $>3$ hours/day' and 'reduced hours of crying per episode' were combined into 'duration of crying'.

After combining the answers, outcomes that were mentioned by $>10 \%$ of participants were forwarded to the shortlist. The threshold of $10 \%$ was chosen by COMMENT to keep the shortlists manageable. A separate shortlist was created for every question: two for HCPs (outpatient and inpatient settings) and two for parents of infants with IC (adequately treated and inadequately treated).

\section{Step $3 b$-Rating the outcomes on the shortlist}

During the second phase of this step, the shortlists for HCPs were sent to HCPs that had agreed previously to take part in this phase. They were asked to rate the clinical relevance of outcomes on the shortlist on a scale of $0-4(0=$ not relevant, $4=$ very relevant $)$ and to prioritise these outcomes by selecting the five outcomes which they thought to be most important to guide their clinical decision-making.

Simultaneously, parents of infants with IC were invited to participate in this phase. Because IC resolves before the age of 5 months and answers were collected anonymously, a new group of parents was approached by their infant's doctor at (general) paediatric outpatient clinics in five countries (Belgium, Croatia, Italy, Poland and The Netherlands). After oral informed consent, they received two shortlists: one with outcomes reported by parents to give them the feeling their child was treated adequately and one with outcomes reported by parents to give them the feeling their child was treated inadequately. We asked them to rank the outcomes on a scale of $0-4(0=$ does not make me feel my child is treated adequately /inadequately, $4=$ makes me feel my child is treated adequately / inadequately) and to prioritise them by selecting the five outcomes that made them feel most as if their child was treated adequately/inadequately. Parents completed the questionnaire either at the outpatient clinic or by telephone. Answers were processed anonymously.

\section{Step 3c-Creating preliminary outcome sets for HCPs and parents}

In line with the COMMENT methodology, ${ }^{21}$ a top five was created for both groups: the five outcomes with the highest rank after rating and prioritising formed the separate preliminary outcome sets for HCPs and parents. Four preliminary outcome sets existed: two for HCPs (outpatient and inpatient settings) and two for parents (adequately treated and inadequately treated).

\section{Step 3d-Creating the final set}

After combining the four preliminary sets (see Results section), a draft COS was presented to an expert panel during the COMMENT Working Group meeting at the 48th annual ESPGHAN meeting in Amsterdam, The Netherlands (2015). Consensus was defined as a unanimous decision from the expert panel.

\section{RESULTS}

\section{Step 1-Preparation: reporting outcome measures in trials of IC}

Our SR demonstrated a lack of agreement about definitions, primary outcome measures and instruments used in intervention trials on IC. ${ }^{18}$

\section{Step 2-Identifying important treatment outcomes}

\section{Healthcare professionals}

In total, 133/143 (93\%) HCPs responded to the first questionnaire (see figure 1). They originated from 29 countries and included 63 paediatric gastroenterologists, 26 general paediatricians, 18 fellows, 8 researchers, 4 residents, 4 nutritionists, 4 others ( 1 intern and 3 not specified), 2 paediatric allergy specialists, 2 neonatologists and 2 general doctors (see figure 2A,B). For the outpatient setting, 50 different outcomes were reported; for the inpatient setting, 59 outcomes were reported (see tables 1 and 2).

\section{Parents}

All 55 parents of infants with IC (as diagnosed by their doctor), originating from five different countries, completed the first questionnaire (see figure 1). In total, parents reported 39 treatment outcomes that made them feel their child was treated adequately and 29 treatment outcomes that made them feel their child was treated inadequately (see tables 3 and 4 ). 


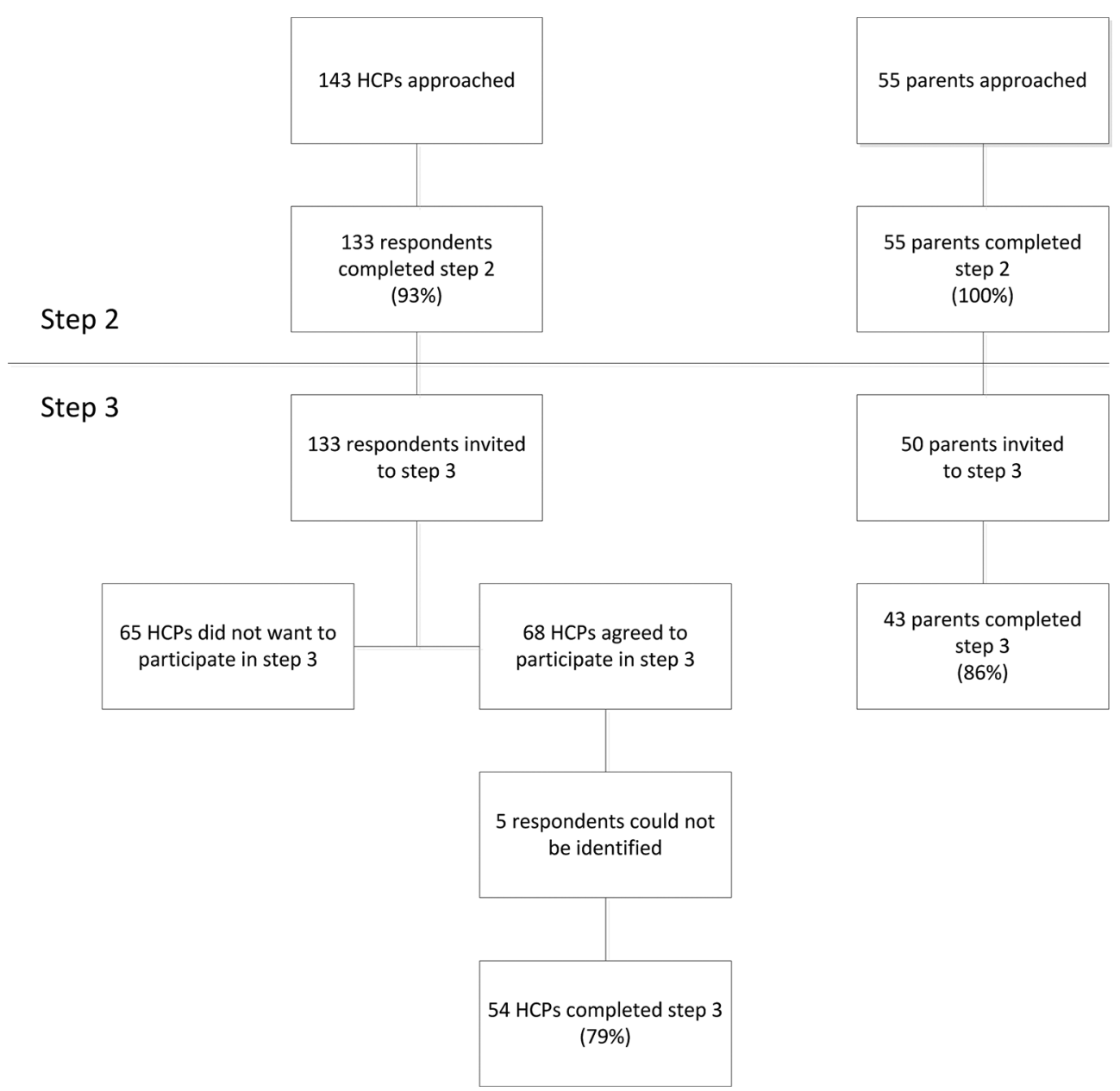

Figure 1 Flowdiagram of respondents. HCPs, healthcare professionals.

\section{Step 3-Creating a shortlist and final COS}

\section{Healthcare professionals}

The shortlists that were developed based on outcomes reported in step 2 are displayed in table 5a. In total, $68 / 133(51 \%)$ HCPs agreed to participate in this step. This group consisted of more paediatric gastroenterologists and general paediatricians $(74 \%)$, compared with the group of non-respondents $(53 \%)$. In the latter group, profession was not specified in $11 \%$ (vs $6 \%$ in the respondent group). In both groups, more than half of the HCPs was European $(68 \%$ vs $56 \%$, in the respondent and non-respondent groups, respectively).

There were more HCPs from South America in the group of respondents $(11 \%)$ compared with the group of non-respondents (2\%). Fifty-four (79\%) HCPs completed the second questionnaire which resulted in two preliminary outcome sets (outpatient and inpatient settings, see table $5 \mathrm{~b}$ ). After comparing these, outcomes for outpatient and inpatient settings turned out to be rather similar-therefore, we combined these preliminary outcome sets into one set, consisting of: 'duration of crying', 'family stress', 'sleeping time of infant', 'quality of life (of family)', 'discomfort of infant' and 'hospital admission/duration'.
Parents

The shortlists that were developed based on reported outcomes in step 2 are displayed in table 6a. In total, $43 / 50$ parents of infants with IC $(86 \%)$ completed the second questionnaire which resulted in two preliminary outcome sets (adequately treated and inadequately treated). The first preliminary outcome set (adequately treated, see table 6b) consisted of: 'no or less crying', 'better infant sleep', 'no or less pain', 'comfortable/happy baby' and 'less irritable/nervous infant'. The second preliminary outcome set (inadequately treated, see table 6b) consisted of: 'constant crying/cannot be soothed', 'sleeping problems of the infant', 'gastrointestinal symptoms', 'worsening of symptoms' and 'appearance of new symptoms'.

\section{Creating the final COS}

When we compared these preliminary outcome sets with the outcome set for HCPs, these appeared to be comparable as well (see tables 5 and 6), except for three outcomes: 'worsening of symptoms', 'gastrointestinal symptoms' and 'appearance of new symptoms'. Therefore, we combined the outcomes mentioned by HCPs and parents into a draft COS: 'duration of crying', 'family stress', 'sleeping time of infant', 'quality of life (of family)', 'discomfort 


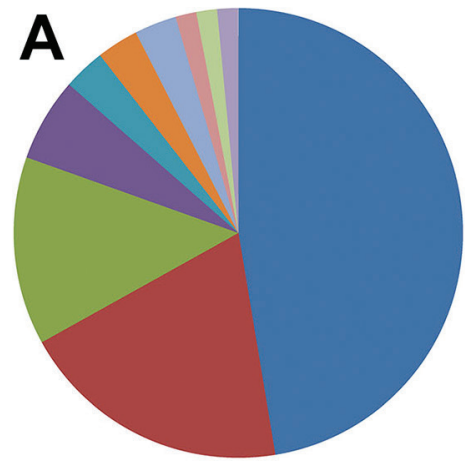

口 Pediatric gastroenterologist / hepatologist $\mathrm{n}=63$

- General pediatrician $n=26$

Fellow $\mathrm{n}=18$

- Researcher $\mathrm{n}=8$

Resident $\mathrm{n}=4$

Nutritionist $\mathrm{n}=4$

Other $\mathrm{n}=4$

- Pediatric allergy specialist $\mathrm{n}=2$

Neonatologist $\mathrm{n}=2$

General medicine $\mathrm{n}=2$

B

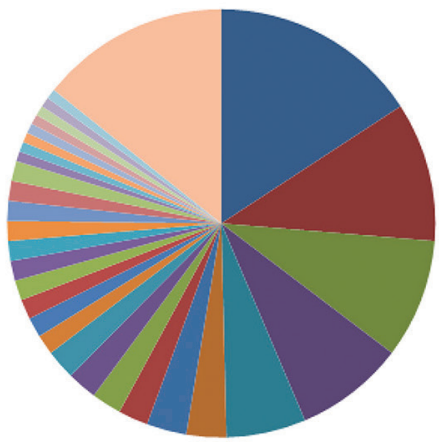

- Italy $n=21$

- The Netherlands $\mathrm{n}=12$

United Kingdom $\mathrm{n}=8$

- Mexico $n=4$

Belgium $n=3$

- Turkey $\mathrm{n}=3$

Australia $\mathrm{n}=2$

- Norway $n=2$

Romania $\mathrm{n}=2$

- France $n=2$

Brazil $n=2$

Finland $\mathrm{n}=1$

Croatia $\mathrm{n}=1$

Russia $n=1$

- Japan $n=1$
口 Israël $n=14$

- Poland $\mathrm{n}=11$

- Germany $n=4$

- Ecuador $\mathrm{n}=3$

Greece $n=3$

- Thailand $n=2$

New Zealand $n=2$

- Czech Republic $\mathrm{n}=2$

- Sweden $\mathrm{n}=2$

- United States $\mathrm{n}=2$

- Canada $\mathrm{n}=1$

Hungary $n=1$

Spain $\mathrm{n}=1$

Phillipines $\mathrm{n}=1$

Not specified $\mathrm{n}=19$

Figure 2 (A) Professional background of healthcare respondents $(n=133)$. (B) Country of practice of healthcare respondents $(n=133)$.

of infant', 'hospital admission/ duration', 'worsening of symptoms', 'gastrointestinal symptoms' and 'appearance of new symptoms'.

This draft COS was thoroughly discussed at the consensus meeting of the COMMENT WG. The WG consisted of general paediatricians, neonatologists and paediatric gastroenterologists. The WG aimed to reach unanimity on each decision that was made. It was unanimously decided not to include 'worsening of symptoms', 'gastrointestinal symptoms' and 'appearance of new symptoms'. In the case of IC, 'worsening of symptoms' refers to increased infant crying, which is already included as 'crying duration'. 'Gastrointestinal symptoms' and 'appearance of new symptoms' were not included because these outcomes cannot, with certainty, be attributed to IC or the effect of treatment. For example, if an infant develops diarrhoea, it is likely that this has a different cause. In addition, 'symptoms' can be very broad and, therefore, multi-interpretable.

The final COS, therefore, consists of 'duration of crying', 'family stress', 'sleeping time of infant', 'quality of life (of family)', 'discomfort of infant' and 'hospital admission/ duration' (see table 7).

\section{DISCUSSION}

Currently, COS are a hot topic in research. Given the heterogeneous outcomes used for IC, we aimed to develop a COS to solve this issue. Using a modified Delphi technique, both HCPs and parents of infants with IC were approached to identify relevant outcomes. Outcomes as mentioned by $>10 \%$ of HCPs and parents turned out to be comparable.

One major strength of our study is the high response rate, which is comparable to, or even higher than, response rates in similar studies. ${ }^{20}{ }^{29}$ About 188/198 (95\%) invited HCPs and parents completed the first questionnaire. The second questionnaire was completed by 97/113 (86\%) HCPs and parents. In total, 97/198 (49\%) invited stakeholders completed both Delphi rounds. Another strength is that we included opinions of HCPs from around the globe. Europe was represented most frequently (58\% of respondents from 17 countries), followed by Asia (16\% of respondents from 5 countries). The input of different cultures increases the applicability of our COS. As stated in a recent SR, only $16 \%$ of studies included public representatives in the development of their COS. Because clinical trials are conducted to assess whether interventions are effective and safe for patients, it is crucial to include outcomes that are important to them. ${ }^{30}$ Given the potential impact IC has on a family, we included outcomes relevant to parents of infants with IC. ${ }^{141531}$

This study has some limitations. First, the use of questionnaires poses us for several potential shortcomings. Because HCPs and parents were asked slightly different questions, this might explain some of the difference in answers. They were developed in English and thereafter 
Table 1 Outcome measures as reported by healthcare professionals for the outpatient setting ( $n=133)$ (six unclear outcomes, such as 'cooperative' and 'eczema/atopy', are not displayed)

\begin{tabular}{|c|c|c|}
\hline \multicolumn{3}{|c|}{ Patient-related outcomes } \\
\hline Domain & Outcome & Total, $\mathbf{n}(\%)$ \\
\hline Crying & $\begin{array}{l}\text { Duration } \\
\text { Frequency } \\
\text { No crying } \\
\text { Intensity/severity of crying }\end{array}$ & $\begin{array}{l}83(62) \\
10(8) \\
6(5) \\
3(2)\end{array}$ \\
\hline Discomfort & Discomfort of child/abdominal distension/pain & $35(26)$ \\
\hline Sleep & $\begin{array}{l}\text { Sleeping time (more/less) } \\
\text { Quality of sleep }\end{array}$ & $\begin{array}{c}25(19) \\
4(3)\end{array}$ \\
\hline Stool & $\begin{array}{l}\text { Normal stools/stool consistency or frequency } \\
\text { Constipation/diarrhoea / blood in stool } \\
\text { Composition of intestinal microbiota }\end{array}$ & $\begin{array}{l}16(12) \\
10(8) \\
1(1)\end{array}$ \\
\hline Feeding & $\begin{array}{l}\text { Feeding (problems/pattern/volume) } \\
\text { Type of feeding (breastfed/formula }+/- \text { probiotics) }\end{array}$ & $\begin{array}{l}19(14) \\
8(6)\end{array}$ \\
\hline Growth & $\begin{array}{l}\text { Thriving/Normal growth/Weight gain } \\
\text { Failure to thrive appearance/weight loss }\end{array}$ & $\begin{array}{l}18(14) \\
3(2)\end{array}$ \\
\hline $\begin{array}{l}\text { Gastrointestinal } \\
\text { problems }\end{array}$ & $\begin{array}{l}\text { Vomiting (blood)/spitting/ regurgitation } \\
\text { Bloating/ gas passing }\end{array}$ & $\begin{array}{l}8(6) \\
5(4)\end{array}$ \\
\hline Stress & Well-being & $12(9)$ \\
\hline Hospital & $\begin{array}{l}\text { Fewer consultations with healthcare professional } \\
\text { Hospital admission }\end{array}$ & $\begin{array}{r}10(8) \\
2(2)\end{array}$ \\
\hline Medication & $\begin{array}{l}\text { Use of probiotics/analgetics/(antireflux) medication } \\
\text { Safety/(no) side effects of medication }\end{array}$ & $\begin{array}{l}7(5) \\
3(2)\end{array}$ \\
\hline Costs & Cost of treatment & $5(4 \%)$ \\
\hline Alarm symptoms & Eg, fever, rectal bleeding, signs of obstruction and recurrent infections & $4(3)$ \\
\hline Other & $\begin{array}{l}\text { (No) adverse events/side effects } \\
\text { Missed organic cause } \\
\text { Harmful: doing any intervention/investigation } \\
\text { Effectivity/feasibility of treatment } \\
\text { Normal development } \\
\text { Any new symptom }\end{array}$ & $\begin{array}{l}8(6) \\
6(5) \\
5(4) \\
2(2) \\
2(2) \\
1(1)\end{array}$ \\
\hline
\end{tabular}

\section{Parent-related outcomes}

\begin{tabular}{llc} 
Domain & Outcome & Total, $\mathbf{n}(\%)$ \\
Quality of life & Quality of life & $18(14)$ \\
& Happy mother/ parents & $7(5)$ \\
& Relationship between parents and infant & $4(3)$ \\
& Restoring parents' daily habits & $3(2)$ \\
& Days absent from work for parents & $2(2)$ \\
& Maternal depression & $2(2)$ \\
Stress & (Reduced) parental/family stress/anxiety & $29(22)$ \\
& Relaxed/coping parents & $6(5)$ \\
& More comfort mom & $4(3)$ \\
Reassurance & Parental/maternal reassurance (+/- education) & $9(7)$ \\
Sleep & (1) sleep mother/parents & $4(3)$ \\
Other & Parent satisfaction & $12(9)$ \\
& No (physical) harm to infant & $6(5)$ \\
& Parents/maternal opinion & $6(5)$ \\
& Parents compliance & $1(1)$ \\
\hline
\end{tabular}


Table 2 Outcome measures as reported by healthcare professionals for the inpatient setting $(n=133)$

(four unclear outcomes, such as 'easy-simple delivery', are not displayed)

\section{Patient-related outcomes}

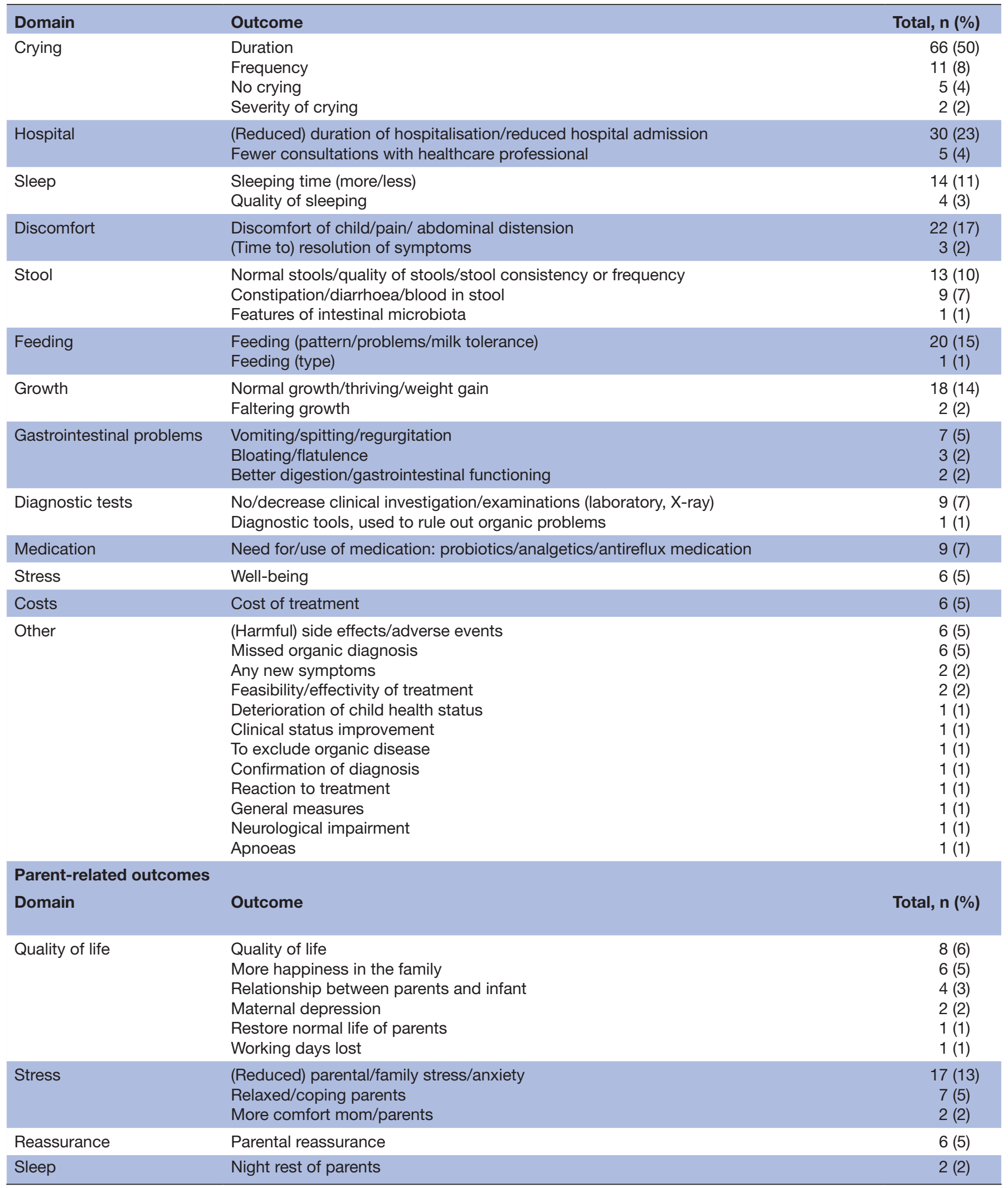


Table 2 Continued

Patient-related outcomes

Other

Parental satisfaction

No (physical) harm to infant

Parental view/concern of severe disease

Structure, rhythm

Nurse satisfaction/staff testimony

Observation of parents handling

Conflict with medical staff

Four unclear outcomes, such as 'easy-simple delivery', are not displayed.

Table 3 Outcome measures that make parents feel their child was treated adequately $(n=55)$

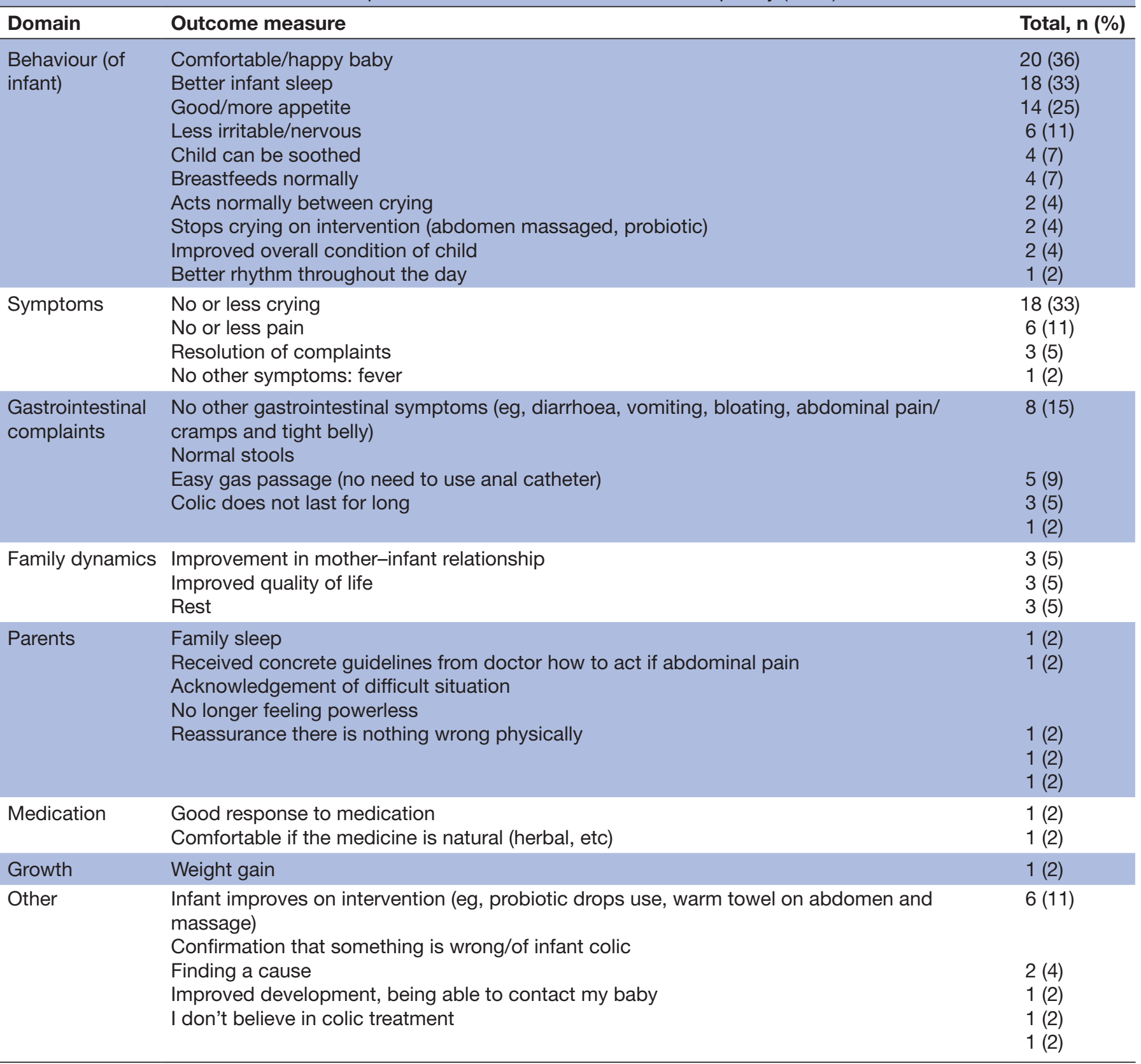


Table 4 Outcome measures that make parents feel their child was treated inadequately $(n=55)$

\begin{tabular}{lll}
\hline Domain & Outcome measure & Total, $\mathbf{n}(\%)$ \\
\hline Behaviour & Constant crying/cannot be soothed & $18(33)$ \\
& Refuses to eat/lack of appetite & $10(18)$ \\
& Sleeping problems/ refuses to sleep & $6(11)$ \\
& Discomfort/pain & $3(5)$ \\
& Child being restless (arching, kicking legs and breathing fast) & $2(4)$ \\
Gastrointestinal & Change in behaviour of baby & (2) \\
complaints & Gastrointestinal problems (eg, bloating, regurgitation, constipation, aerophagia, vomiting, & $44(80)$ \\
& flatulence, nausea and colic/abdominal pain/severe cramps) \\
& Stool problems (loose stools and too many stools)
\end{tabular}

\begin{tabular}{|c|c|c|}
\hline & & $\begin{array}{l}4(7) \\
1(2)\end{array}$ \\
\hline $\begin{array}{l}\text { General } \\
\text { symptoms }\end{array}$ & $\begin{array}{l}\text { No clear effect of treatment } \\
\text { Appearance of new symptoms } \\
\text { Worsening of symptoms }\end{array}$ & $\begin{array}{l}11(20) \\
8(15) \\
5(9)\end{array}$ \\
\hline Parents & $\begin{array}{l}\text { No uncomfortable feelings/worries } \\
\text { Not feeling understood }\end{array}$ & $\begin{array}{l}2(4) \\
1(2)\end{array}$ \\
\hline Family dynamics & Separation of mother and child due to treatment & $1(2)$ \\
\hline Growth & Not gaining weight & $1(2)$ \\
\hline Other & $\begin{array}{l}\text { If treatment would have a negative effect on physical/mental development } \\
\text { Disturbing adverse gastroenterological symptoms occur } \\
\text { Costly and no guarantees of success } \\
\text { I don't believe in colic treatment }\end{array}$ & $\begin{array}{c}1(2) \\
1(2) \\
1(2) \\
1(2)\end{array}$ \\
\hline
\end{tabular}

translated. Since this was not done by a professional translator, it is possible that subtle changes in questions or answers arose. Furthermore, we may have misinterpreted answers, especially when we combined answers that were comparable in our opinion. Another potential limitation is the use of the 5-point Likert scale, for the rating of the importance of the outcome measures, instead of the 7- or 9-point Likert scale. The latter options would have improved nuance in the results. It has been stated, however, that respondents might not be able to differentiate properly between more than five potential answers. ${ }^{32}$

Second, we collected data from HCPs at two international paediatric gastroenterology conferences. This may have caused bias because they might be more focused on gastrointestinal causes for IC than other HCPs treating patients with IC. Including HCPs from for instance, the developmental field might have given a different perspective, although it should be emphasised that the outcomes in our COS are not related to gastrointestinal causes of IC. We did not decide a priori which subtypes of HCPs had to be included. It was only decided to include HCPs working in primary, secondary and/or tertiary care that had experience with treating infants with IC. The inclusion of specialist nurses or well child nurses might have been valuable as well, as they are part of the multidisciplinary team that parents encounter in some countries. However, infants with IC are often referred to general paediatricians or paediatric gastroenterologists, represented by $67 \%$ of respondents. Furthermore, in several participating countries, healthcare is organised in such a manner that paediatricians represent primary care as well (eg, Italy, France and Poland). Third, although we included respondents from around the globe, responses from Northern America (2\%) and South East Asia (3\%) were minimal. Fourth, it should be noted that some of the outcomes mentioned by parents were not included in the COS. In keeping with the methodology used by COMMENT, $^{21}$ the consensus meeting consisted solely of HCPs. Due to logistic and financial reasons, we were unable to invite parents of infants with IC to this WG meeting. This WG unanimously decided that the occurrence of some outcomes, such as 'appearance of new symptoms', cannot, with certainty, be explained by IC or the effect of treatment. However, clinicians should pay attention to beliefs and worries of parents at all times.

'Hospital admission/duration' might seem a peculiar core outcome measure to some COS users. Occasionally, 
Table 5A Shortlist outcome measures healthcare professionals (rated and prioritised)

\begin{tabular}{|c|c|c|c|}
\hline Rank & Outcome measure & $\begin{array}{l}\text { Average } \\
\text { rating }\end{array}$ & Percentage \\
\hline \multicolumn{4}{|c|}{ Outpatient setting } \\
\hline 1 & Duration of crying & 3.57 & 93 \\
\hline 2 & Family stress & 3.50 & 85 \\
\hline 3 & Sleeping time of infant & 2.91 & 76 \\
\hline 4 & Quality of life & 3.15 & 65 \\
\hline 5 & Discomfort of infant & 2.78 & 69 \\
\hline 6 & Feeding problems & 2.69 & 57 \\
\hline 7 & Growth & 2.72 & 39 \\
\hline 8 & Stool consistency/frequency & 1.91 & 11 \\
\hline \multicolumn{4}{|c|}{ Inpatient setting } \\
\hline 1 & Duration of crying & 3.56 & 91 \\
\hline 2 & Family stress/anxiety & 3.39 & 80 \\
\hline 3 & Hospital admission/duration & 3.19 & 80 \\
\hline 4 & Discomfort of infant & 2.87 & 72 \\
\hline 5 & Sleeping time of infant & 2.78 & 67 \\
\hline 6 & Feeding problems & 2.80 & 54 \\
\hline 7 & Growth & 2.67 & 41 \\
\hline 8 & $\begin{array}{l}\text { Stool consistency / } \\
\text { frequency }\end{array}$ & 1.81 & 11 \\
\hline
\end{tabular}

however, excessively crying infants may be admitted to hospital to unburden the crisis situation at home. ${ }^{33}$

Currently, the WG on IC has completed three out of four steps of the COS project. So far, we focused on which outcomes should be measured in trials on IC. In our next step, we will search for (validated) instruments to measure these outcomes. It should be noted that this COS should function as a 'dynamic COS'. If our understanding of IC changes, the COS should evolve over time. Furthermore, since COS have the potential to improve evidence-based healthcare, we need to consider ways to implement this COS, so it will be available to relevant communities. ${ }^{24}$ Finally, to enable comparison of trial results, there is a need for homogeneity in outcomes and consensus on the definition of IC. Therefore, we recommend that the recently published and internationally accepted Rome IV criteria for IC should be used in future trials of IC. ${ }^{5}$

Clinical trials are only as credible as their endpoints. ${ }^{34}$ There is a need to develop COS for other common

\begin{tabular}{ll}
\hline Table 5B Preliminary outcome set healthcare professionals \\
\hline Outpatient setting & Inpatient setting \\
\hline Duration of crying & Duration of crying \\
\hline Family stress & Family stress/ anxiety \\
\hline Sleeping time of infant & Sleeping time of infant \\
\hline Discomfort of infant & Discomfort of infant \\
Quality of life & Hospital admission/duration \\
\hline
\end{tabular}

Table 6A Shortlist outcome measures parents (rated and prioritised)

\begin{tabular}{|c|c|c|c|}
\hline Rank & Outcome measure & $\begin{array}{l}\text { Average } \\
\text { rating }\end{array}$ & Percentage \\
\hline \multicolumn{4}{|c|}{ Adequately treated } \\
\hline 1 & Comfortable/happy baby & 3.79 & 81 \\
\hline 2 & No or less pain & 3.74 & 79 \\
\hline 3 & No or less crying & 3.72 & 79 \\
\hline 4 & Less irritable/nervous & 3.58 & 70 \\
\hline 5 & Better infant sleep & 3.44 & 60 \\
\hline 6 & $\begin{array}{l}\text { Infant improves on } \\
\text { intervention }\end{array}$ & 3. 33 & 49 \\
\hline 7 & $\begin{array}{l}\text { No other gastrointestinal } \\
\text { symptoms }\end{array}$ & 3. 37 & 40 \\
\hline 8 & Good/more appetite & 2.91 & $33 \%$ \\
\hline \multicolumn{4}{|c|}{ Inadequately treated } \\
\hline 1 & Worsening of symptoms & 3.88 & 91 \\
\hline 2 & $\begin{array}{l}\text { Constant crying/cannot be } \\
\text { soothed }\end{array}$ & 3.42 & 84 \\
\hline 3 & Gastrointestinal symptoms & 3.23 & 79 \\
\hline 4 & Sleeping problems & 3.00 & 65 \\
\hline 5 & $\begin{array}{l}\text { Appearance of new } \\
\text { symptoms }\end{array}$ & 3.33 & 54 \\
\hline 6 & No clear effect of treatment & 3.16 & 58 \\
\hline 7 & $\begin{array}{l}\text { Refuses to eat/lack of } \\
\text { appetite }\end{array}$ & 2.98 & 63 \\
\hline
\end{tabular}

disorders such as functional constipation and gastro-oesophageal reflux disease as well.

\section{CONCLUSION}

The COS for IC consists of the following outcomes: duration of crying, family stress, sleeping time of infant, quality of life (of family), discomfort of infant and hospital admission/duration. It should serve as a minimum of outcomes to be measured and reported. This will facilitate and improve evidence synthesis, by enhancing homogeneity. Finally, it will enable the evaluation of effectiveness in therapeutic trials of IC. Therefore, we recommend researchers to use this COS when setting up a new clinical trial or performing an SR on IC.

Table 6B Preliminary core outcome sets parents

\begin{tabular}{ll}
\hline Adequately treated & Inadequately treated \\
\hline No or less crying & $\begin{array}{l}\text { Constant crying/cannot be } \\
\text { soothed }\end{array}$ \\
\hline Better infant sleep & Sleeping problems \\
No or less pain & Gastrointestinal symptoms \\
Comfortable/happy baby & Worsening of symptoms \\
\hline Less irritable/nervous & Appearance of new symptoms \\
\hline
\end{tabular}


Table 7 Final core outcome set for infant colic

\section{Duration of crying}

Family stress

Sleeping time of infant

Quality of life of family

Discomfort of infant

Hospital admission/duration

Acknowledgements We thank all the healthcare professionals and parents of infants with infant colic for their valuable contributions.

Contributors NFS carried out the initial analyses, drafted the initial manuscript and approved the final manuscript as submitted. MWL contributed to data analysis, critically reviewed the manuscript and approved the final manuscript as submitted. JJK coordinated and supervised data collection, critically reviewed the manuscript and approved the final manuscript as submitted. MAB, FI, and HS conceptualized and designed the study, critically reviewed the manuscript and approved the final manuscript as submitted. MMT conceptualized and designed the study, contributed to data analysis, critically reviewed the manuscript and approved the final manuscript as submitted.

Competing interests None declared.

Provenance and peer review Not commissioned; externally peer reviewed.

Data sharing statement All data generated or analysed during this study are included in this article and its supplementary information files.

Open Access This is an Open Access article distributed in accordance with the Creative Commons Attribution Non Commercial (CC BY-NC 4.0) license, which permits others to distribute, remix, adapt, build upon this work non-commercially, and license their derivative works on different terms, provided the original work is properly cited and the use is non-commercial. See: http://creativecommons.org/ licenses/by-nc/4.0/

(C) Article author(s) (or their employer(s) unless otherwise stated in the text of the article) 2017. All rights reserved. No commercial use is permitted unless otherwise expressly granted.

\section{REFERENCES}

1. Sullivan P. Gastroenterology and nutrition. Training in paediatrics The essential curriculum. 1st ed: Oxford University Press, 2009:108.

2. Crotteau CA, Wright ST, Eglash A. Clinical inquiries. what is the best treatment for infants with colic? J Fam Pract 2006;55:634-6.

3. Kilgour T, Wade S. Infantile colic. Clin Evid 2005: p.362-72.

4. Iacono G, Merolla R, D'Amico D, et al; Paediatric Study Group on Gastrointestinal Symptoms in Infancy. Gastrointestinal symptoms in infancy: a population-based prospective study. Dig Liver Dis 2005;37:432-8.

5. Benninga MA, Faure C, Hyman PE, et al. Childhood functional gastrointestinal disorders: neonate/Toddler. Gastroenterology 2016:1443-55.

6. Savino F, Castagno E, Bretto R, et al. A prospective 10-year study on children who had severe infantile colic. Acta Paediatr Suppl 2005;94:129-32.

7. Reijneveld SA, van der Wal MF, Brugman E, et al. Infant crying and abuse. Lancet 2004;364:1340-2.

8. Wolke D, Rizzo P, Woods S. Persistent infant crying and hyperactivity problems in middle childhood. Pediatrics 2002;109:1054-60.

9. Canivet C, Jakobsson I, Hagander B. Infantile colic. Follow-up at four years of age: still more "emotional". Acta Paediatr 2000;89:13-17.

10. Romanello S, Spiri D, Marcuzzi E, et al. Association between childhood migraine and history of infantile colic. Jama 2013;309:1607-12.

11. Qubty W, Gelfand AA. The link between infantile colic and migraine. Curr Pain Headache Rep 2016;20:31.
12. Smarius LJ, Strieder TG, Loomans EM, et al. Excessive infant crying doubles the risk of mood and behavioral problems at age 5: evidence for mediation by maternal characteristics. Eur Child Adolesc Psychiatry 2017;26.

13. Vandenplas $Y$, Abkari A, Bellaiche $M$, et al. Prevalence and health outcomes of functional gastrointestinal symptoms in infants from birth to 12 months of age. J Pediatr Gastroenterol Nutr 2015;61:531-7.

14. Radesky JS, Zuckerman B, Silverstein M, et al. Inconsolable infant crying and maternal postpartum depressive symptoms. Pediatrics 2013;131:e1857-e1864.

15. Vik T, Grote V, Escribano J, et al; European Childhood Obesity Trial Study Group. Infantile colic, prolonged crying and maternal postnatal depression. Acta Paediatr 2009;98:1344-8.

16. Indrio F, Di Mauro A, Riezzo G, et al. Prophylactic use of a probiotic in the prevention of colic, regurgitation, and functional constipation: a randomized clinical trial. JAMA Pediatr 2014;168:228-33.

17 Shamir R, St James-Roberts I, Di Lorenzo C, et al. Infant crying, Colic, and gastrointestinal discomfort in early childhood: a review of the evidence and most plausible mechanisms. J Pediatr Gastroenterol Nutr 2013;57(Suppl 1):S1-45.

18. Steutel NF, Benninga MA, Langendam MW, et al. Reporting outcome measures in trials of infant colic. J Pediatr Gastroenterol Nutr 2014;59:341-6.

19. Sinha IP, Altman DG, Beresford MW, et al; StaR Child Health Group. Standard 5: selection, measurement, and reporting of outcomes in clinical trials in children. Pediatrics 2012;129(Suppl 3):146-152.

20. Sinha IP, Gallagher R, Williamson PR, et al. Development of a core outcome set for clinical trials in childhood asthma: a survey of clinicians, parents, and young people. Trials 2012;13:103.

21. Karas J, Ashkenazi S, Guarino A, et al; Consensus Group on Outcome Measures Made in Paediatric Enteral Nutrition Clinical Trials (COMMENT). A core outcome set for clinical trials in acute diarrhoea. Arch Dis Child 2015;100:359-63.

22. Reijneveld SA, Brugman E, Hirasing RA. Excessive infant crying: the impact of varying definitions. Pediatrics 2001;108:893-7.

23. Xu M, Wang J, Wang N, et al. The efficacy and safety of the probiotic bacterium lactobacillus reuteri DSM 17938 for infantile colic: a Meta-Analysis of randomized controlled trials. PLOS One 2015;10:e0141445.

24. The COMET initiative. Secondary . http://www.comet-initiative.org/ (Accessed on 3rd July 2015).

25. Tugwell P, Boers M, Brooks P, et al. OMERACT: an international initiative to improve outcome measurement in rheumatology. Trials 2007;8:38.

26. Koletzko B, Szajewska H, Ashwell M, et al; Early Nutrition Academy and European Society for Paediatric Gastroenterology, Hepatology and Nutrition Committee on Nutrition - Consensus Group on Outcome Measures Made in Paediatric Enteral Nutrition Clinical Trials. Documentation of functional and clinical effects of infant nutrition: setting the scene for COMMENT. Ann Nutr Metab 2012;60:222-32.

27. Kirkham JJ, Gorst S, Altman DG, et al. Core outcome SetSTAndards for reporting: the COS-STAR statement. PLOS Med 2016;13:e1002148.

28. Sinha I, Jones L, Smyth RL, et al. A systematic review of studies that aim to determine which outcomes to measure in clinical trials in children. PLoS Med 2008;5:e96.

29. Potter S, Holcombe C, Ward JA, et al; BRAVO Steering Group. Development of a core outcome set for research and audit studies in reconstructive breast surgery. Br J Surg 2015;102:1360-71.

30. Gargon E, Gurung B, Medley N, et al. Choosing important health outcomes for comparative effectiveness research: a systematic review. PLoS One 2014:9:e99111.

31. Wake M, Morton-Allen E, Poulakis Z, et al. Prevalence, stability, and outcomes of cry-fuss and sleep problems in the first 2 years of life: prospective community-based study. Pediatrics 2006;117:836-42.

32. Wikipedia.https://nl.wikipedia.org/wiki/Likertschaal. Accessed on January 23, 2017.

33. Dutch centre for youth healthcare. Multidisciplinaire richtlijn: Preventie, signalering, diagnostiek en behandeling van excessief huilen bij baby's https://www.nvk.nl/Portals/0/richtlijnen/huilbaby/ huilbaby.pdf (Accessed on 3rd November 2016).

34. Tugwell P, Boers M. OMERACT conference on outcome measures in rheumatoid arthritis clinical trials: introduction. J Rheumatol 1993;20:528-30. 